\title{
Neonatal mortality and causes of death in Kersa Health and Demographic Surveillance System (Kersa HDSS), Ethiopia, 2008-2013
}

Nega Assefa ${ }^{1 *}$ D, Yihune Lakew², Betelhem Belay ${ }^{1}$, Haji Kedir ${ }^{1}$, Desalew Zelalem', Negga Baraki ${ }^{1}$, Melake Damena ${ }^{1}$, Lemessa Oljira', Wondimye Ashenafi ${ }^{1}$ and Melkamu Dedefo ${ }^{1,3}$

\begin{abstract}
Background: In the world, Neonatal mortality accounts for $40 \%$ of death of children under the age of 5 years. Majority of neonatal deaths occur in developing countries outside of formal health system, among which death in the first hour of first day of their life constitute the huge bulk. This analysis is intended to estimate neonatal mortality rates and identify the leading causes of death based on the surveillance data over 6 years period in Kersa health and demographic surveillance system (Kersa HDSS) site, Eastern Ethiopia.

Methods: Kersa HDSS is an open dynamic cohort of population established in 2007. The surveillance started after conducting a baseline census followed by population update and events registration on house-to-house visits every 6 months. Data were collected using verbal autopsy (VA) questionnaire from close relatives (usually mothers in this case) and causes of deaths were assigned by 2 to 3 physicians. This analysis was done based on 301 neonatal deaths and 10,934 live births occurred during 2008 to 2013.

Results: The overall neonatal death rate during the study period was 27.5 per 1000 live births. Nearly all neonatal deaths (94\%) occurred at home. More than four-fifth (82.4\%) of the deaths was occurred in the first week of life. More than $80 \%$ of the deaths were due to perinatal causes. Bacterial sepsis of the newborn accounted for $31.2 \%$ followed by birth asphyxia and perinatal respiratory disorder (28.2 \%), and prematurity (17.3\%). Higher number of death was observed in Tolla and Bereka sub-districts located at the southern parts of the study site which are away from the main road network.

Conclusion: The overall neonatal mortality over 6 years is the same to the national average (27 per 1000 live births). The leading causes of neonatal death were bacterial sepsis of newborn and birth asphyxia. Communitybased skilled health care delivery during birth should be emphasized.
\end{abstract}

Keywords: Neonatal deaths, Causes of death, Verbal autopsy, Kersa HDSS, Ethiopia

\section{Background}

Under 5 mortality remains 1 of the biggest public health concern constituting $7 \cdot 2$ million in 2011, of which $2 \cdot 2$ million were early neonatal, and $0 \cdot 7$ million late neonatal deaths [1]. Neonatal deaths account for $40 \%$ of under 5 mortality [2]. Based on data collected from 193 countries in 2012, the global and Sub-Saharan neonatal mortality rate was 21 and 32 per 1000 live births, respectively.

\footnotetext{
* Correspondence: negaassefa@yahoo.com

${ }^{1}$ College of Health and Medical Sciences, Haramaya University, P.O.Box 1494, Harar, Ethiopia

Full list of author information is available at the end of the article
}

About $99 \%$ of neonatal deaths were from low and middle income countries, of which $66 \%$ (1.16 million deaths) are in Africa and Southeast Asia [3].

In the same report, the top 5 countries with the greatest number of neonatal deaths were India, Nigeria, Pakistan, China, and Democratic Republic of Congo. According to the 2013 and 2014 report, Ethiopia ranked $6^{\text {th }}$ in neonatal deaths $[3,4]$. The 2012-2014 global data indicated that the 3 major causes of neonatal death were preterm birth complications (35\%), neonatal infections (23\%) and intrapartum related complications (23\%). 
These causes account for nearly $80 \%$ of deaths in this age group [3-8].

Majority of the neonatal deaths in developing countries occur outside the formal health system. As a result, many studies on the causes of death of children under the age of 5 excluded neonatal deaths mainly for 2 reasons; 1 is poor reporting on a sign and symptoms that leads to death and the other is the number of cases reported is very small in number. To resolve this, some researchers tried to group neonatal deaths as 'other' childhood or 'perinatal' causes, which has created difficulty to identify causes deaths associated with the neonatal [9]. Recently, several studies have focused exclusively on the use of VA for the newborn deaths, making this an opportune time to assess the current state of knowledge and provide direction for future research efforts [10].

In Ethiopia, due to the absence of vital event registration, most deaths are left undocumented. As the vast majority of deaths occur outside the health system, the ability of health facilities to generate representative statistics is limited in the country [9]. In this regard, the use of verbal autopsy (VA) from health and demographic surveillance system is the most promising interim solution for this problem [11-13].

Reducing under 5 mortality rate by two third was Millennium Development Goal number 5 (MDG-5) that ends in 2015 and Ethiopia is 1 of the countries achieved this goal. However, the rates disaggregated by age showed that neonatal mortality continues to be suspended high with little or no sign of reduction over years $[5,14]$. Focusing on under-five mortality in general and neonatal mortality in particular continues to be the focus during Sustainable Development Goal (SDG) period [15].

Consistent to the SDG goals, Ethiopia has also developed a health sector strategic plan to direct its health intervention through 2035. In this plan, the country aspires to be a middle income country averting unnecessary neonatal mortality [16]. Therefore, it is imperative to substantiate with findings on the ground if the country is in the right direction over the years bench marking the end period of MDG.

Hence, information generated using the existing data from Kersa HDSS will help in providing estimate of neonatal mortality and the leading causes of death to support evidence-based decision making at different levels.

\section{Methods}

\section{Kersa HDSS Site}

The site was established in September 2007 and located at the eastern Hararge of the Oromyia regional state in eastern Ethiopia. The district capital, Kersa, is located $44 \mathrm{~km}$ from Harar, west direction. The district has 3 climatic zones with the altitude ranging from 1400 to 3200 meters above sea level (Fig. 1). This surveillance site covers 12 kebeles, the lowest administrative units (2 urban and 10 rural) from 38 randomly selected kebeles (As of January 2015, it is increased to 24 Kebeles). The site started its surveillance on 10,256 households and 52,470 population in 2007 and by 2013, the population has increased to 62,550 . In the move to double the size of population and households under surveillance, by 2015, as the number of Kebeles doubled from 12 to 24, the size of the population has increased to 129,000 and the number of households to 27,000 . Kersa HDSS is a member of INDEPTH network of Health and Demographic Surveillance System (HDSS) sites in the world [17]. In Kersa HDSS, there are a total of 19 health facilities; including 4 health centers, 10 health posts and 5 clinics. There are 7 research team members, 22 vital events enumerators, 4 verbal autopsy interviewers (VAIs), 5 field supervisors, 2 data managers, and 6 data clerks [18].

\section{Study design and population}

Kersa HDSS is an open dynamic cohort study design that longitudinally follow a well-defined entities or primary subjects (individuals, households, and residential units) and all related socio-demographic and health related outcomes within a clearly defined geographic area. The surveillance was started by conducting a baseline census of the population including housing and socioeconomic characteristics. Then, population update and events registration on house-to-house visits to register all pregnancy observations and outcomes, deaths, marriage and in-and-out migration has been done every 6 months. Subsequently, any causes of death in the population from registered deaths were identified using Verbal Autopsy (VA) [18].

\section{Verbal autopsy questionnaire}

There are 3 verbal autopsy forms (deaths up to 28 completed days of life-neonatal deaths; deaths to children between 4 weeks and 14 years of age; and deaths to persons aged 15 years and above), adopted from the 2007 standardized World Health Organization (WHO) questionnaires [19-21]. The verbal autopsy forms and questionnaire was translated in to Oromefa language for use in the field. The questionnaires were used for collecting information, such as, age, sex, place of death, sign and symptoms observed during the late life period of the deceased. In addition, a short narrative history of the course of disease that leads to death, health services used in the period before death, and documentation of any medical evidence available at the household, including whether a health worker informed the respondent of the cause of death. Particularly, for the neonatal form, the condition of the mother during and after pregnancy and birth was used. The questionnaire also contain the 


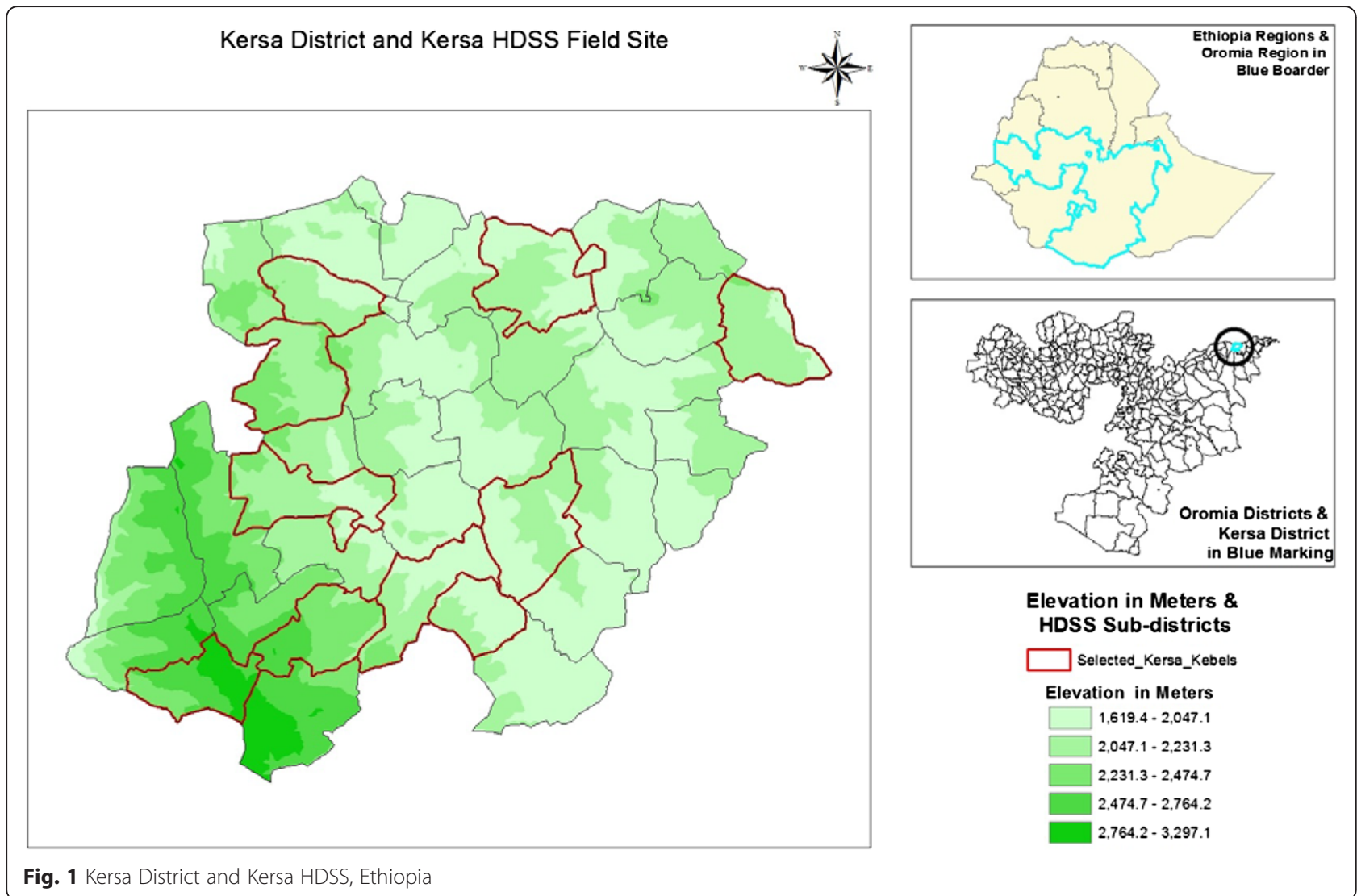

symptom duration checklist arranged loosely around anatomical systems and are intended to be as informative as possible in leading a positive diagnosis of probable cause of death, as well as, the confident exclusion of differential diagnoses [18].

\section{VA data collection procedure}

The process begins with a report of a death occurring to a resident of the area by the local data collectors. The regular vital event interviewers receive these reports and maintain records of deaths that occur in their working areas using event recording form. The information in the death event recording form is later transferred to death registration book that is kept in the field office for referral purpose. Copy of the recording form with location information is given to the VA interviewer to complete the VA interview after the appropriate mourning period. The vital event interviewers help the VA interviewers to arrange an appointment with the family of the deceased to conduct the VA interview. This was within 1-3 months after a death with due consideration to culturally appropriate mourning periods. On the day of interview, the VA interviewer arrives at the residence of the deceased to conduct the interview with an adult person (with a mother in this case) at the deceased households. When it is difficult to get a reliable respondent, the VA interviewer arranges an appointment to visit the household on another day when a more informed respondent will be available. Up to 3 attempts were made to conduct an interview if the information given is incomplete after 3 visits, the VA interviewer completes the VA form with the information that is available. A note that the interview is incomplete due to the absence of reliable respondents was made on the form in the 'history of events' section. These events are counted as deaths in the system, although the cause of death will remain unknown. Again, every section of the form was filled in accurately before the form is submitted to the research team for onward processing.

\section{Causes of death assignment}

Two physicians, trained in VA diagnosis and coding procedures for the study, assigned codes and titles, up to 3 causes of death (underlying, immediate and contributing factor) independently using information contained in VA forms based on the WHO International Classification of Disease-10 (ICD-10) and VA code system. After checking agreements of physician assigned underlying cause of death based on VA coding discordant cases were sent to the third physician again for independent review and diagnosis. If any of 2 of these 3 physicians assigned an underlying cause of death to the same VA code, this was considered as 
the final cause of death; otherwise, the causes were labeled as undetermined. In the analysis, 18 cases (6\%) cause of death were not determined based on the 3 physician report.

\section{VA data quality controls}

Individuals who have completed at least a high school education and who have been working in the field during the last 1 year was continued to work as VA interviewers. They received 3 days training on the questionnaires, recording, contacting close relatives and data collection procedures. The training curriculum include sessions on discussion of individual symptoms, and their description in local language for easy recognition by the respondents and demonstration of interviewing techniques by research team members. The VA interviewer was informed about new deaths by the resident enumerators and conduct verbal autopsy interviews. Researcher team members coordinate the field activities of all vital events registration and VA interviewers are responsible for making sure that the field operations run smoothly and efficiently and also give supervisory support to events data collectors and VA interviewers. During the course of the fieldwork, supervisors continually visit the sites to check on the progress and sort out problems that may have been encountered by enumerators.

\section{Data management and analysis}

Neonatal mortality rate was calculated using the total neonatal death divided by total number of births during the 6 years period. Causes of death were analyzed by some basic socio-demographic characteristics. Tables and graphs were used to summarize and present the data. STATA version 11 software and excel sheet were used for data analysis. Geographic Information System (GIS) mapping is used to plot the extent of death over the map against the sub-district cumulative deaths. Cross tabulations of death events by sex, age and other background characteristics was provided. $95 \%$ confidence interval for neonatal death rate is calculated for sub districts and $p$-value for 0.05 is taken to determine level of significance.

\section{Ethical approval}

Kersa HDSS site has received ethical clearance from the Ethiopian Science and Technology Agency, Ethiopian Public Health Association (EPHA), US Center for Disease Control and Prevention (CDC) and the Health Research Ethics Review Committee (HRERC) of Haramaya University. To capture occurrence of vital events to any family member, head of a family or an eligible adult among the family was interviewed. Therefore, informed verbal consent was obtained from head of the family or eligible adult among the family. This consent procedure was stated in the proposal which was approved by the ethical review committee. To keep confidentiality, data containing personal identifiers of subjects were not shared to third party.

\section{Results}

During the period from 2008 to 2013, a total of 301 neonatal deaths were recorded. The lowest proportions of neonatal deaths were observed in $2012(13.0 \%)$ and in 2013 (13.0\%). The highest proportion of neonatal deaths were seen in 2009 (20.9 \%) and in 2010 (20.6 \%) (Table 1). As shown in Table 2, the overall neonatal death rate in the study period was 27.5 per 1000 live births.

Over the 6 years period (2008-2013) $61 \%$ of the deceased were male neonates and $39 \%$ were females. Among the deceased neonates, more than four-fifth $(82.4 \%)$ of the deaths occurred in the first week of birth and the rest were in the remaining 3 weeks of neonatal period.

Table 1 Demographic characteristics of the deceased by surveillance years, Kersa HDSS site in Ethiopia

\begin{tabular}{|c|c|c|c|c|c|c|c|c|}
\hline \multirow{3}{*}{$\begin{array}{l}\text { Background } \\
\text { characteristics }\end{array}$} & \multicolumn{8}{|c|}{ Surveillance years and number of neonatal deaths } \\
\hline & \multirow{2}{*}{$\begin{array}{l}2008 \\
n\end{array}$} & \multirow{2}{*}{$\begin{array}{l}2009 \\
n\end{array}$} & \multirow{2}{*}{$\begin{array}{l}2010 \\
n\end{array}$} & \multirow{2}{*}{$\begin{array}{l}2011 \\
n\end{array}$} & \multirow{2}{*}{$\begin{array}{l}2012 \\
\mathrm{n}\end{array}$} & \multirow{2}{*}{$\begin{array}{l}2013 \\
n\end{array}$} & \multicolumn{2}{|c|}{$2008-2013$} \\
\hline & & & & & & & $\mathrm{n}$ & Death fraction with $95 \% \mathrm{Cl}$ \\
\hline \multicolumn{9}{|l|}{ Residence } \\
\hline Urban & 3 & 3 & 1 & 9 & 0 & 1 & 17 & $5.6[3.44-8.71]$ \\
\hline Rural & 44 & 60 & 61 & 42 & 39 & 38 & 284 & 94.4 [91.29-96.56] \\
\hline \multicolumn{9}{|l|}{ Sex } \\
\hline Male & 28 & 34 & 44 & 32 & 23 & 23 & 184 & $61.1[55.53-66.52]$ \\
\hline Female & 19 & 29 & 18 & 19 & 16 & 16 & 117 & $38.9[33.48-44.47]$ \\
\hline \multicolumn{9}{|l|}{ Age at death } \\
\hline $0-7$ days & 47 & 53 & 52 & 41 & 29 & 26 & 248 & 82.4 [77.78-86.39] \\
\hline 8-28 days & 0 & 10 & 10 & 10 & 10 & 13 & 53 & 17.6 [13.61-22.25] \\
\hline Total & 47 & 63 & 62 & 51 & 39 & 39 & 301 & \\
\hline
\end{tabular}


Table 2 Neonatal death rate over the study period between 2008 and 2013, Kersa HDSS in Ethiopia

\begin{tabular}{llll}
\hline Surveillance years & Neonatal deaths & Live births & NMR with 95 \% Cl \\
\hline 2008 & 47 & 1616 & $29.1[21.7-38.2]$ \\
2009 & 63 & 1756 & $35.9[27.9-45.4]$ \\
2010 & 62 & 1983 & $31.3[24.3-39.6]$ \\
2011 & 51 & 1549 & $32.9[24.9-42.7]$ \\
2012 & 39 & 1770 & $22.0[15.9-29.7]$ \\
2013 & 39 & 2260 & $17.3[12.5-23.3]$ \\
$2008-2013$ & 301 & 10,934 & $27.5[24.6-30.7]$ \\
\hline
\end{tabular}

NMR-Neonatal Mortality Rate

Although it shows persistent decline, the pattern of neonatal and early neonatal death rates over the course of the study period was significantly higher than late neonatal death rates. The late neonatal death rate remains relatively constant over the study period with no declining pattern (Table 2 and Fig. 2).

Over the 6 years period, a statistically significant higher death rate was observed among male newborns compared to female newborns. The gap in male and female newborn deaths was highest in 2010. A decreasing pattern was also documented in both male and female newborn death rates over the study period (Fig. 3).

Of the total neonatal deaths observed during the 6 years period, the vast majority $(94.4 \%)$ occurred in rural parts of the study area, and only 17 (5.6\%) were occurred in urban areas. Nearly all neonatal deaths (94\%) occurred at home and the remaining were in hospital and health centers. As depicted in Fig. 4, over the study period, a relatively highest neonatal death rate was recorded in 2 villages of Bereka and Tolla followed by other neighboring villages that are located in southern parts of the study site.

\section{Causes of neonatal deaths}

Based on the broad classification of causes of neonatal deaths, more than $80 \%$ of the deaths were due to perinatal causes. Deaths due to circulatory diseases, external causes and gastro-intestinal diseases account for only $1 \%$ of neonatal deaths while $3.3 \%, 6 \%$, and $6.3 \%$ of neonatal deaths were due to infectious or parasitic diseases, undetermined causes and unspecified causes, respectively (Fig. 5).

With regard to the specific causes of neonatal death, bacterial sepsis of the newborn accounts for $31.2 \%$, while it is closely followed by birth asphyxia and perinatal respiratory disorder $(28.2 \%)$, and prematurity (17.3\%). Other causes of deaths are other diseases related to the perinatal period $(3.3 \%)$ and acute lower respiratory infection $(2.7 \%)$ (Table 3$)$.

As part of neonatal causes, the leading causes of death for early neonatal period (from birth to 7 days) were birth asphyxia and perinatal respiratory disorder (33.1\%), bacterial sepsis of newborn follows (24.2\%) and prematurity (including respiratory distress) (20.2\%) (Table 4). The late neonatal (8-28 days) causes of deaths where dominated by bacterial sepsis of newborn $(64.2 \%)$ and acute lower respiratory infection including pneumonia $(7.5 \%)$ (Table 5). As indicated in Table 6, over the study period, in most of the Kebeles, the leading causes of neonatal death were bacterial sepsis of newborn, birth asphyxia and prematurity including respiratory distress.

\section{Discussion}

The cumulative average neonatal mortality rate was 27 per 1000 live births. This is lower than many of the reports from countries in Africa and other developing countries in Asia like Pakistan and Bangladesh [3, 4, 22-25]. The rate reported by the present study is consistent to the

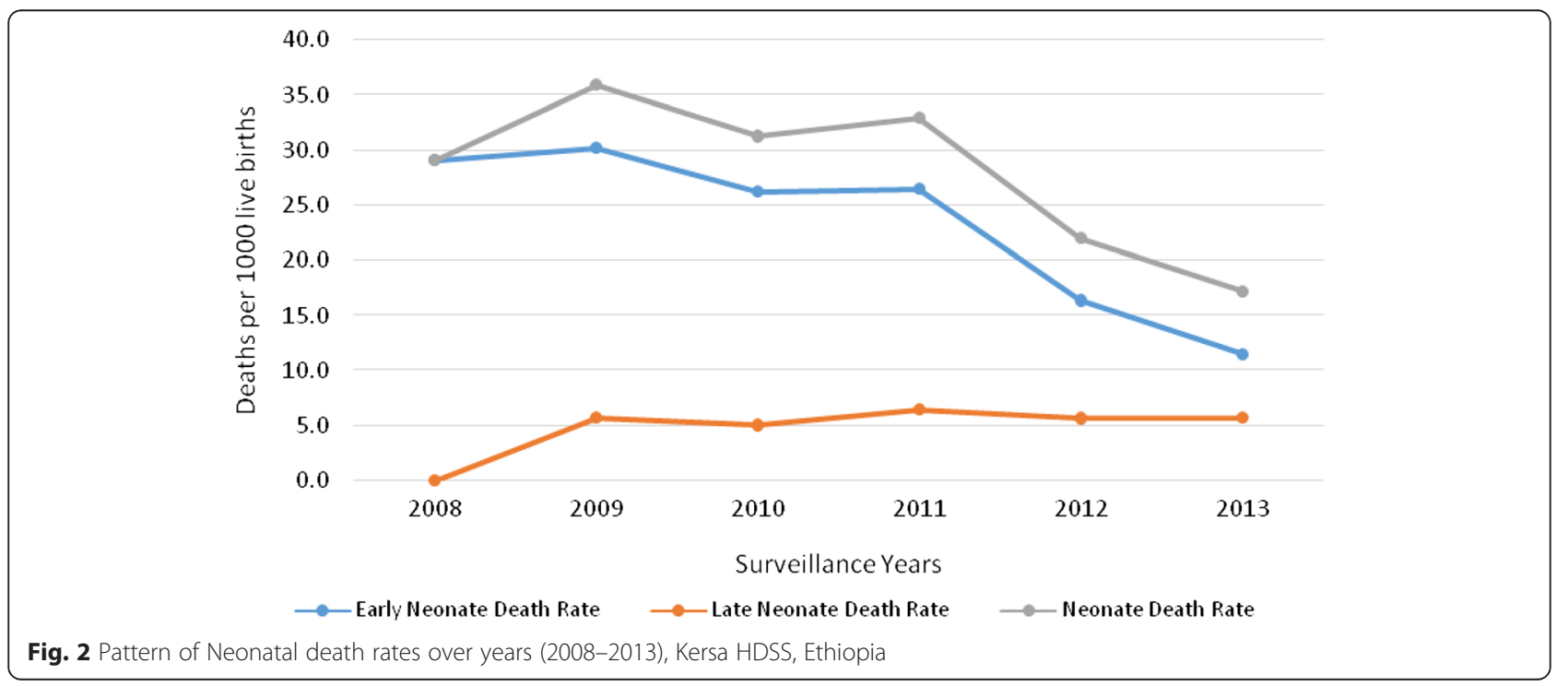




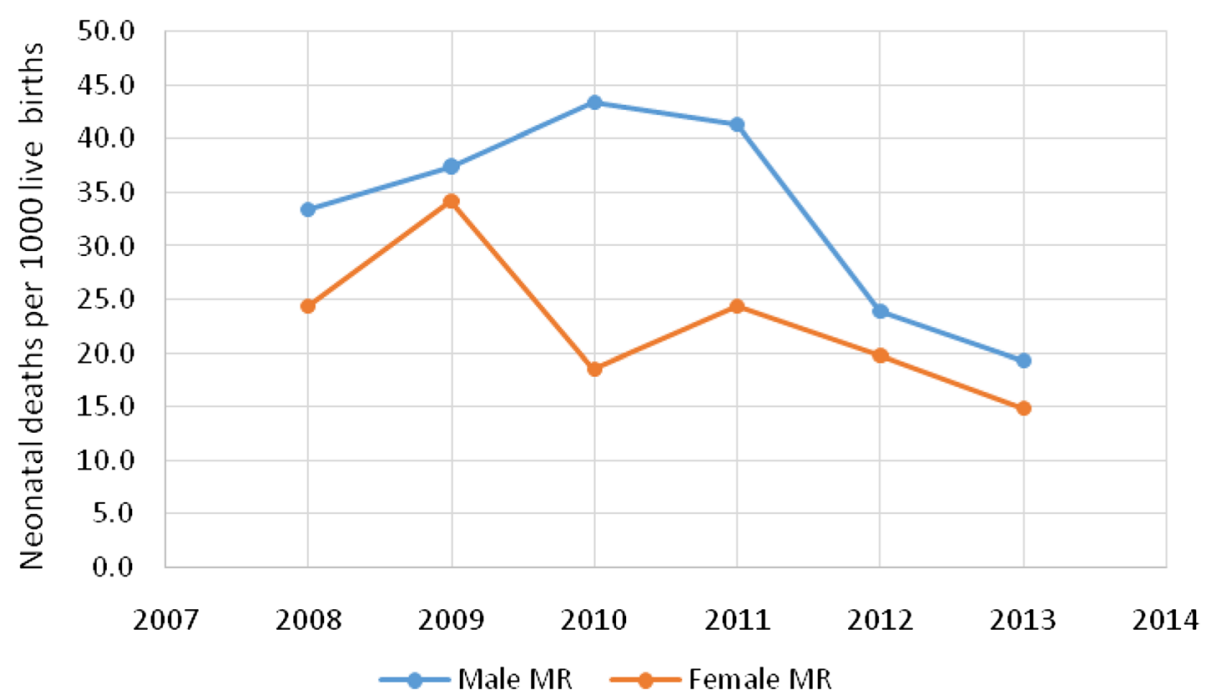

Fig. 3 Difference between male and female neonatal death over the years (2008-2013), Kersa HDSS, Ethiopia

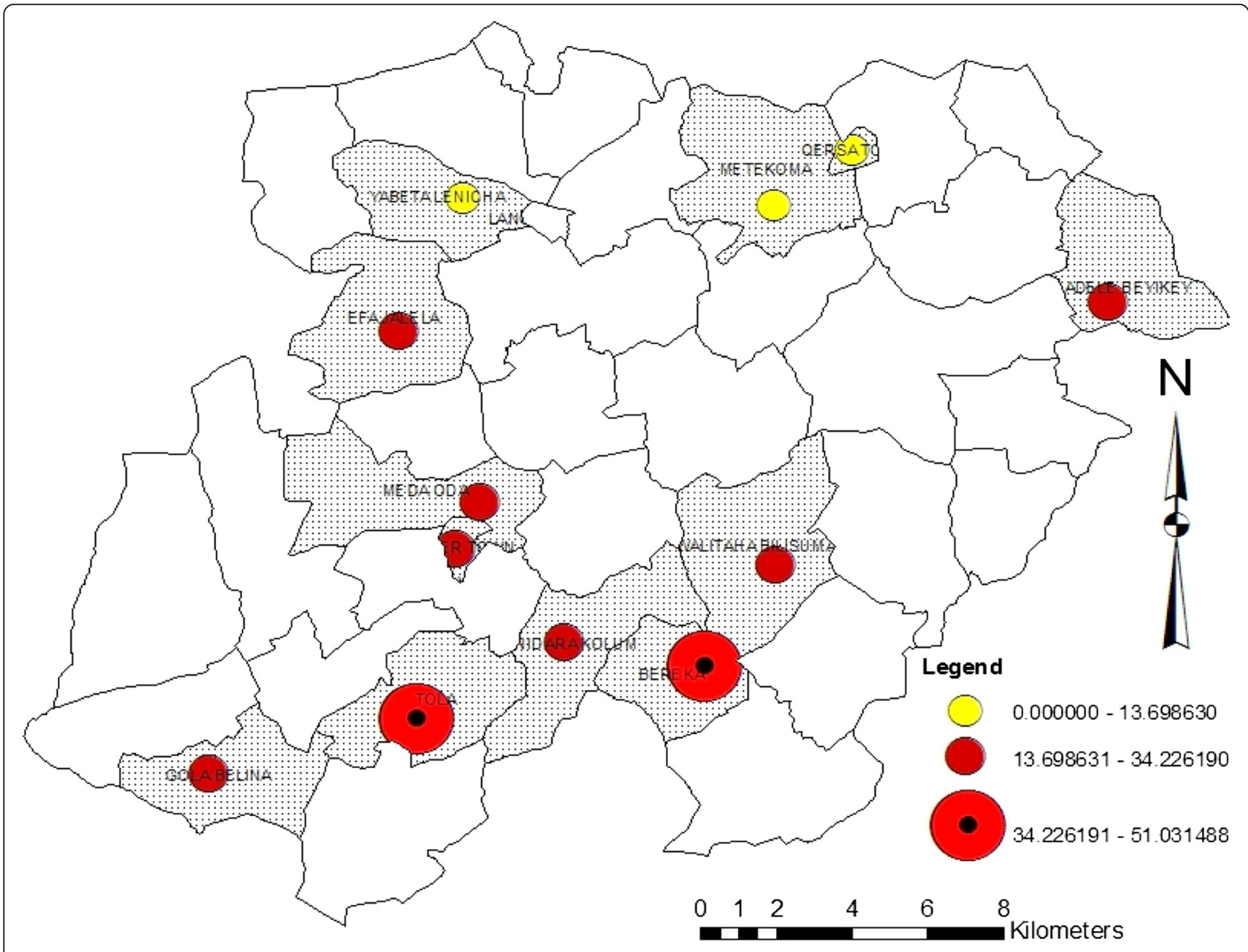

Fig. 4 Sum of 2008-2013 Neonatal death rate distribution in sub-districts of Kersa HDSS, Ethiopia 


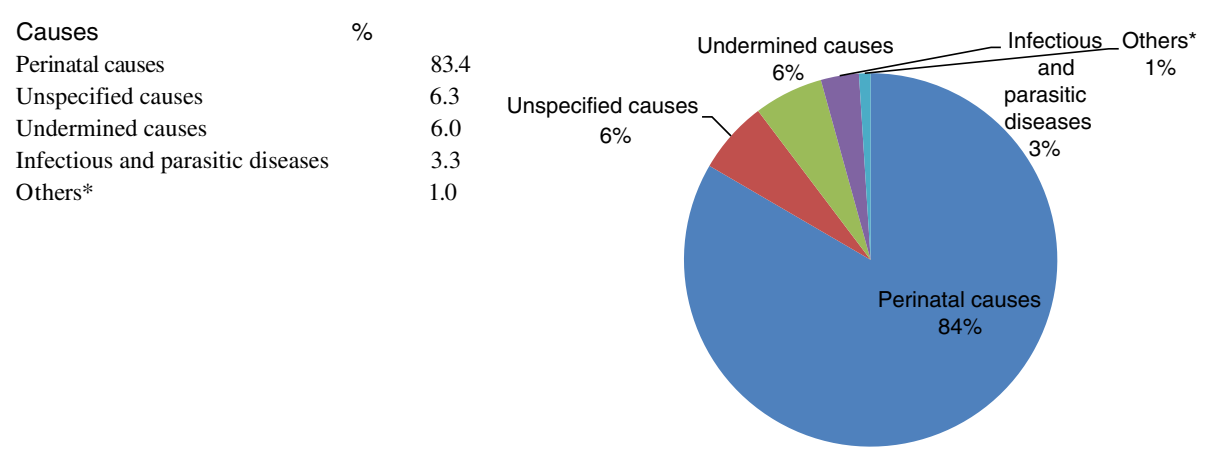

Fig. 5 Percent of broad causes of neonatal death in 2008-2013, Kersa HDSS, Ethiopia. *Others include diseases of the circulatory system, external causes of death and gastrointestinal disorders with cases less than 5

previous study in south west Ethiopia around Bonke district of Gamo Gofa zone [26], however it is lower than the 35.5 per 1000 live births that has been recently reported from southwest Ethiopia around Jimma Zone [27]. The differences in the reports could be attributed to the timing and differences in the settings of the 2 studies. The lower level of neonatal mortality in the present study could be partly explained due to the fact that the present study was conducted on health and demographic surveillance site (HDSS) and the population in such setting could have better awareness about the health issues. The neonatal mortality rate seems to reduce over the study period, however, the level of cumulative average of neonatal mortality observed in this study is nearly what is considered to be high and calls for policy attention [28].

The findings revealed that neonatal deaths observed over 6 years period were mainly males that nearly

Table 3 Specific neonatal causes of death from 2008-2013, Kersa HDSS in Ethiopia

\begin{tabular}{|c|c|c|}
\hline \multirow[t]{2}{*}{ Causes of death } & \multicolumn{2}{|c|}{ 2008-2013 } \\
\hline & Deaths & $\begin{array}{l}\text { Cause of death fraction } \\
\text { with } 95 \% \mathrm{Cl}\end{array}$ \\
\hline Acute lower respiratory infection & 8 & $2.7[1.24-4.98]$ \\
\hline Bacterial sepsis of newborn & 94 & $31.2[26.18-36-64]$ \\
\hline $\begin{array}{l}\text { Birth asphyxia and perinatal } \\
\text { respiratory disorder }\end{array}$ & 85 & $28.2[23.37-33.53]$ \\
\hline $\begin{array}{l}\text { Other diseases related to the } \\
\text { perinatal period }\end{array}$ & 10 & $3.3[1.70-5.84]$ \\
\hline $\begin{array}{l}\text { Prematurity (including } \\
\text { respiratory distress) }\end{array}$ & 52 & $17.3[13.32-21.86]$ \\
\hline Others $^{a}$ & 15 & $5.0[2.92-7.91]$ \\
\hline Undetermined cause of death & 18 & $6.0[3.70-9.11]$ \\
\hline Unspecified causes of death & 19 & $6.3[3.96-9.51]$ \\
\hline Total & 301 & \\
\hline
\end{tabular}

accounted for 3 out of 5 neonatal deaths and most deaths occurred at home and among the rural part of the study area. This is in agreement with other reports from elsewhere and in Ethiopia [23, 29]. Consistent to other studies, most of neonatal deaths occurred during the first 7 days of birth [8, 22, 30, 31]. Most neonatal deaths occurred at home and during the first week of life imply that the observed level of neonatal mortality could be attributed to lack of skilled birth assistance as home deliveries are the major place of delivery in the study area [32, 33]. The absence of neonatal Intensive Care Unit (ICU) in the area has also contributed for unabated neonatal mortality.

The study also revealed that sepsis, birth asphyxia and prematurity accounted for three-fourth or more of early neonatal deaths, while sepsis is the commonest cause of late neonatal death, contributing to more than $60 \%$ of neonatal deaths occurring to this age group. These are

Table 4 Specific early neonatal causes of death from 2008-2013, Kersa HDSS in Ethiopia

\begin{tabular}{|c|c|c|}
\hline \multirow[t]{2}{*}{ Causes of death } & \multicolumn{2}{|c|}{$2008-2013$} \\
\hline & Deaths & $\begin{array}{l}\text { Cause of death fraction } \\
\text { with } 95 \% \mathrm{Cl}\end{array}$ \\
\hline Bacterial sepsis of newborn & 60 & $24.2[19.17-29.84]$ \\
\hline $\begin{array}{l}\text { Birth asphyxia and perinatal } \\
\text { respiratory disorder }\end{array}$ & 82 & $33.1[27.42-39.10]$ \\
\hline $\begin{array}{l}\text { Other diseases related to } \\
\text { the perinatal period }\end{array}$ & 8 & $3.2[1.51-6.03]$ \\
\hline $\begin{array}{l}\text { Prematurity (including } \\
\text { respiratory distress) }\end{array}$ & 50 & $20.2[15.52-25.50$ \\
\hline Others $^{a}$ & 17 & $6.9[4.18-10.53]$ \\
\hline Undetermined causes of death & 15 & $6.0[3.56-9.56]$ \\
\hline Unspecified causes of death & 16 & $6.5[3.87-10.05]$ \\
\hline Total & 248 & \\
\hline
\end{tabular}


Table 5 Specific late neonatal causes of death from 2008-2013, Kersa HDSS in Ethiopia

\begin{tabular}{|c|c|c|}
\hline \multirow[t]{2}{*}{ Causes of death } & \multicolumn{2}{|c|}{ 2008-2013 } \\
\hline & Deaths & $\begin{array}{l}\text { Cause of death fraction } \\
\text { with } 95 \% \mathrm{Cl}\end{array}$ \\
\hline $\begin{array}{l}\text { Acute lower respiratory infection } \\
\text { including pneumonia }\end{array}$ & 4 & 7.5 \\
\hline Bacterial sepsis of newborn & 34 & 64.2 \\
\hline $\begin{array}{l}\text { Birth asphyxia and perinatal } \\
\text { respiratory disorder }\end{array}$ & 3 & 5.7 \\
\hline $\begin{array}{l}\text { Congenital malformation, } \\
\text { other and unspecified }\end{array}$ & 1 & 1.9 \\
\hline Congestive heart failure & 1 & 1.9 \\
\hline $\begin{array}{l}\text { Other diseases related to the } \\
\text { perinatal period }\end{array}$ & 2 & 3.8 \\
\hline $\begin{array}{l}\text { Prematurity (including } \\
\text { respiratory distress) }\end{array}$ & 2 & 3.8 \\
\hline Undetermined causes of death & 3 & 5.7 \\
\hline Unspecified causes of death & 3 & 5.7 \\
\hline Total & 53 & 100.0 \\
\hline
\end{tabular}

consistent to the previous reports on the cause of neonatal mortality $[4,5,8,24,26]$.

Recently, other studies have indicated that sepsis is the major cause of late neonatal death [5]. Delivery complications are associated with odds of neonatal deaths. The world Health organization estimated the most direct causes of neonatal deaths to be preterm birth, severe infection and asphyxia [34].

Previous research from Bangladesh [25], Tanzania [35] Pakistan [36] and Ethiopia [27] have consistently established that birth asphyxia is 1 of the major causes of death. These findings imply that most of the neonatal deaths are mainly due to lack of access to skilled birth assistance and complications of labor and delivery.
The report also indicted the highest number of deaths in the southern part of the district in Tola and Baraka villages. These villages are away from the main road and their access to health care is limited due to terrain and poor feeding road network. This is an important implication to further focus on community based skilled birth attendants in resource limited setting.

Ethiopia has strived to reach every family with basic health service using a home born strategy referred to as "Health Extension Program" [37, 38]. The health extension program is designed to provide basic health promotion activities principally to the rural community. Though, the services rendered by this program are sixteen health promotion packages including family planning, antenatal, delivery and postnatal care $[39,40]$, the toll of neonatal death at the early days of neonatal life persists.

Reports on the rate and cause of neonatal death helps countries to track their performance towards the set national and international targets $[15,16]$. Many of the earlier reports are based on estimates of data from clinical setting, which doesn't represent the health condition in the general population. This report is based on a verbal autopsy for the deceased neonates from the ongoing health and demographic surveillance system in the rural Ethiopia; hence it gives a good bench mark to track the performance of SDG and Ethiopian health sector strategic plan in the future.

The verbal autopsy generate information through conversations with family members of the deceased, the VA method uses information on circumstances leading to death, including symptoms and signs during terminal illness to assign causes of death [41-45]. The VA method has been used in different resource constraint countries to develop a viable mid or long-term strategy for improving neonatal mortality. It is a popular and reliable method for community diagnoses of major causes of death in developing countries, where majority of the

Table 6 Neonatal death rates and leading causes per Kebele in the period from 2008-2013, Kersa HDSS site

\begin{tabular}{lllll}
\hline Study villages & Deaths & LB & NNM rate & Leading causes of death (COD) \\
\hline Qersa town & 5 & 397 & 12.6 & Bacterial sepsis of newborn \\
Metekoma & 10 & 730 & 13.7 & Bacterial sepsis of newborn \\
Yabeta Lencha & 820 & 1113 & 27.0 & Bacterial sepsis of newborn \\
Ifa Jalela & 30 & 850 & 27.1 & Prematurity including Respiratory Distress (RD) \\
Mede Oda & 23 & 529 & 22.7 & Bacterial sepsis of newborn and prematurity RD \\
Weter Town & 12 & 1249 & 26.4 & Bacterial sepsis of newborn and birth asphyxia \\
Handhura Kossum & 33 & 921 & 51.0 & Bacterial sepsis of newborn and birth asphyxia \\
Tolla & 47 & 672 & 34.2 & Bacterial sepsis of newborn and birth asphyxia \\
Gola Belina & 23 & 645 & 49.6 & Birth asphyxia \\
Bereka & 32 & 1378 & 21.0 & Bacterial sepsis of newborn \\
Walteha Bilisuma & 29 & 1530 & 32.0 & Birth asphyxia \\
Adele Key Key & 49 & &
\end{tabular}


deaths occur at home. It has been demonstrated to produce valid estimates of cause-specific mortality fractions in many settings [11].

Limitations of this method are problem of remembering the state of health condition for someone during the late periods of life that introduce recall bias, the reported health problems might not be exactly the same conditions felt by the deceased that introduce reporting error, and the agreement of physician to diagnose based on reported health condition might introduced misclassification. In order to reduce these errors it was advised to collect the information from close relatives with the best knowledge relatives could remember, in this case from the mother or father of the baby [12, 23, 27, 44, 45].

\section{Conclusion}

The cumulative neonatal mortality over 6 year period is 27 per 1000 live birth. Over years it showed a little decline without significant difference between subsequent years. Early neonatal death contributed to majority of the neonatal deaths. Perinatal causes of death; sepsis, birth asphyxia and prematurity accounted for three-fourth or more of early neonatal deaths, while sepsis is the commonest cause of late neonatal death. Increasing access to skilled birth attendant in the community setting through the health extension program by improving the approach to delivery service could avert preventable neonatal deaths.

\section{Abbreviations}

CDC, Center for Disease Control and Prevention; EPHA, Ethiopian Public Health Association; GIS, Geographic Information System; HDSS, Health and Demographic Surveillance System; HRERC, Health Research Ethics Review Committee; ICD-10, International Classification of Disease-10; MDG, Millennium Development Goal; SDG, Sustainable Development Goal; VA, Verbal Autopsy; WHO, World Health Organization

\section{Acknowledgments}

The authors would like to acknowledge Center for Disease Control and Prevention (CDC), Ethiopian Public Health Association (EPHA) and Haramaya University for supporting Kersa HDSS. We are also thankful for study participants, data collectors and supervisors in the surveillance.

\section{Funding}

Kersa HDSS has been supported by the President's Emergency Plan for AIDS Relief (PEPFAR) through US Center for Disease Control and Prevention (CDC), in accordance with the EPHA-CDC Cooperative Agreement GH001039-01.

\section{Availability of data and materials}

Any set of data will be available for anyone in need upon filling the agreement and you can find a stable web link to the data sharing policy at: http://www.haramaya.edu.et/research/projects/kds-hrc/kdshrc-project-data/ kds-hrc-data-sharingpolicydocument/. The data sharing agreement form will be accessed through this link: http://www.haramaya.eduet/research/projects/ kds-hrc/kds-hrc-project-data/kdshrc-data-sharing-agreement/. For any kind of inquiry concerning data you can contact the first author (negaassefa@yahoo.com).

\section{Authors' contributions}

$N A, Y L, B B$, and $H K$ conceptualized the manuscript. NA, $Y L, B B$, and $H K$ and performed the data analysis, made interpretations and drafted the manuscript. NA, YL, BB, HK, LO, MD, NB, WA, DZ and MD reviewed the manuscript and approved the final version.

\section{Competing interests}

The authors declare that they have no competing interests.

\section{Consent for publication}

Not applicable.

\section{Ethics approval and consent to participate}

Kersa HDSS site has received ethical clearance from the Ethiopian Science and Technology Agency, Ethiopian Public Health Association (EPHA), US Center for Disease Control and Prevention (CDC) and the Health Research Ethics Review Committee (HRERC) of Haramaya University. Informed consent was obtained from head of the family or eligible adult among the family. To keep confidentiality, data containing personal were made anonymous.

\section{Disclaimer}

The findings and conclusions in this report are those of the authors and do not necessarily represent the official position of the Centers for Disease Control and Prevention/the Agency for Toxic Substances and Disease Registry.

\section{Author details}

${ }^{1}$ College of Health and Medical Sciences, Haramaya University, P.O.Box 1494, Harar, Ethiopia. ${ }^{2}$ Ethiopian Public Health Association, Addis Ababa, Ethiopia.

${ }^{3}$ College of Computing and Informatics, Haramaya University, Harar, Ethiopia.

Received: 19 April 2016 Accepted: 8 July 2016

Published online: 19 July 2016

\section{References}

1. Rafael L, Haidong W, Kyle JF, Julie KR, Mohsen N, Jake RM, Laura D, Katherine TL, David P, Charles A, et al. Progress towards Millennium Development Goals 4 and 5 on maternal and child mortality: an updated systematic analysis. Lancet. 2011;378:1139-65.

2. Lawn JE, et al. Health Policy Plan. Lancet. 2012;79(9832):2151-61.

3. UNICEF, WHO, Worldbank, UNFPA. Levels and trends in child mortality report 2012. New York: UNICEF; 2013.

4. UNICEF, WHO, Worldbank, UNFPA. Levels and trends in child mortality report 2013. New York: UNICEF, WHO, Worldbank, and UNFPA; 2014

5. Liv L, Jonson $\mathrm{H}$, Cousens $\mathrm{S}$, et al. Global, regnal and national causes of child mortality: updated system analysis. 2012.

6. UNICEF. Levels and Trends in Child Mortality- Report 2012. 2012.

7. UNICEF, WHO, BANK TW, Division UNDP. Levels \& Trends in Child Mortality. In: Report on Estimates Developed by the UN Inter-agency Group for Child Mortality Estimation. 2011.

8. Bassani D, Jha P. Causes of neonatal and child mortality in India: nationally representative mortality survey. Lancet. 2010;376(9755):1853-60.

9. Lulu K, Berhane Y. The use of simplified verbal autopsy in identifying causes of adult death in a predominantly rural population in Ethiopia. BMC Public Health. 2005;5:58.

10. Kutschera J, Reiterer F, Müller W, Urlesberger B. Neonatology and Pediatric Intensive Care. In: 33 th annual meeting of the Society for Neonatology and Pediatric Intensive Care 2007; 2005 jun 14-16. Hamburg: Z Geburtsh Neonatol; 2007.

11. Begg S, Rao C, Lopez A. Design options for sample-based mortality surveillance. Int J Epidemiol. 2005:34(5):1080-7.

12. Chandramohan D, Maude G, Rodrigues L, Hayes R. Verbal Autopsies for Adult Deaths: Issues in their Development and Validation. Int J Epidemiol. 1994;23:213-22.

13. Velkoff $V$, Setel P. Sample vital Registration using Verbal Autopsy: A new approach for collecting mortality data. In: International Programs Center Population Division. Atlanta: US Census Bureau; 2005.

14. Liu L, Oza S, Hogan D, Perin J, Rudan I, Lawn JE, Cousens S, Mathers C, Black RE. Global, regional, and national causes of child mortality in 2000-13, with projections to inform post-2015 priorities: an updated systematic analysis. Lancet. 2015;385:430-40.

15. WHO. Towards a monitoring framework with targets and indicators for the health goals of the post-2015 Sustainable Development Goals. Geneva: World Helath Organization; 2015.

16. $\mathrm{FMOH}$-Ethiopia. Envisioning Ethiopia's Path towards Unviersal Helath Coverae Through Strengthning Primary Health Care. Addis Ababa: Federal Minstry of Health; 2015. 
17. INDEPTH. Delivering Better Health Information Driving Better Health Policy The Past, The Present and The Future. Acra: Ghana INDEPTH Network; 2014.

18. Assefa N, Oljira L, Baraki N, Demena M, Zelalem D, Ashenafi W, Dedefo M. Profile of Kersa HDSS: the Kersa Health andDemographic Surveillance System. Int J Epidemiol. 2015;1:8.

19. Measure Evaluation. Verbal Autopsy Interviewer's Manual, SAWY Sample Vital Registration with Verbal Autopsy system. Washington: MEASURE Evaluation project; 2007.

20. WHO. Verbal Autopsy Standards. The 2007 verbal autopsy instrument. Release 1. Geneva: WHO; 2007.

21. WHO. Verbal Autopsy Standards. Ascertaining and attributing cause of death. Geneva: WHO; 2007.

22. Jehan I, Harris H, Salat S, Zeb A, Mobeen N, Pasha O, McClure E, Janet M, Wright L, Goldenberg R. Neonatal mortality, risk factors and causes: a prospective population based cohort study in urban Pakistan. Bull World Health Organ. 2009;130:138.

23. Mekonnen Y, Tensou B, Telake DS, Degefie T, Bekele A. Neonatal mortality in Ethiopia: trends and determinants. BMC Public Health. 2013;13:483.

24. UNICEF, Worldbank WHO, UNFPA. Levels and trends in child mortality report 2011. WHO, Worldbank, and UNFPA: UNICEF; 2012.

25. Chowdhury HR, Thompson S, Ali M, Alam N, Yunus M, Streatfiel PK. Causes of Neonatal Deaths in a Rural Subdistrict of Bangladesh: Implications for Intervention. J HEALTH POPUL NUTR. 2010:28(4):375-82.

26. Yaya Y, Eide KT, Norheim OF, Lindtjørn B. Maternal and Neonatal Mortality in South-West Ethiopia: Estimates and Socio-Economic Inequality. PLoS ONE. 2014;9(4):e96294. doi:96210.91371/journal.pone.0096294.

27. Debelew GT, Afework MF, Yalew AW. Determinants and Causes of Neonatal Mortality in Jimma Zone, Southwest Ethiopia: A Multilevel Analysis of Prospective Follow Up Study. PLoS ONE. 2014;9:e107184. doi:107110.101371/journal.pone.0107184.

28. CSA. Ethiopia Demographic and Health Survey 2011. Addis Ababa: Central Statstics Authority, ICF, International; 2012.

29. Gizaw M, Molla M, Mekonnen $W$. Trends and risk factors for neonatal mortality in Butajira District, South Central Ethiopia, (1987-2008): a prospective cohort study. BMC Pregnancy Childbirth. 2014;14:64.

30. Khatun F, Rasheed S, Moran AC, Alam AM, Shomik MS, Sultana M, Choudhury N, Bhuiya MI. Causes of neonatal and maternal deaths in Dhaka slums: Implications for service delivery. BMC Public Health. 2012;12:84.

31. Fottrell E, Osrin D, Alcock G, Azad K, Bapat U, Beard J. Cause-specific neonatal mortality: analysis of 3772 neonatal deaths in Nepal, Bangladesh, Malawi and India. Arch Dis Child Fetal Neonatal. 2015;F1:F9.

32. Assefa N, Berhane Y, Worku A. Pregnancy rates and pregnancy loss in Eastern Ethiopia. Acta Obstet Gynecol Scand. 2013.

33. Lee AC, Cousens S, Darmstadt GL, Blencowe H, Pattinson R, Moran NF Hofmeyr GJ, Haws RA, Bhutta SZ, Lawn JE. Care during labor and birth for the prevention of intrapartum-related neonatal deaths: a systematic review and Delphi estimation of mortality effect. BMC Public Health. 2011;11(3):S10.

34. Lawn JE, Cousens S, Zupan J, Team LNSS. 4 million neonatal deaths: when? Where? Why? Lancet. 2005;365(9462):891-900.

35. Ersdal HL, Mduma E, Svensen E, Perlman J. Birth Asphyxia: A Major Cause of Early Neonatal Mortality in a Tanzanian Rural Hospital. Pediatrics. 2012;129:e1238-43.

36. Jehan I, Harris H, Salat S, Zeb A, Mobeen N, Pasha O, McClure EM, Moore J, Wright LL, Goldenberg RL. Neonatal mortality, risk factors and causes: a prospective population-based cohort study in urban Pakistan. Bull World Health Organ. 2009;87:130-8.

37. Girma S, G/Yohannes A, Kitaw Y, Ye-Ebiyo Y, Seyoum A, Desta H, Teklehaimanot A. Human Resource Development for Health in Ethiopia: Challenges of Achieving the Millennium development Goals. Ethiop J Health Dev. 2007;21(3):216-31.

38. El-Saharty S, Kebede S, Dubusho PO, Siadat B. Improving Health Service Delivery. In: Health, Nutrition and Population (HNP) Discussion Paper. The World Bank. 2009.

39. $\mathrm{FMOH}$. Health and Health related indicator. Planning and Programming Department Federal Ministry of Health: Addis Ababa; 2007.

40. FMoH. Health Extension Program in Ethiopia: Profi le. In: Center HeaE, editor. Addis Ababa: Federal Ministry of Health (ET). 2007.

41. Andreas J, et al. Evaluation of a village-informant riven demographic surveillance system. Demogr Res. 2007;16:8.
42. Mobley C, Boerma J, Titus S, Lohrke B, Shangula K, Black R. Validation study of a verbal autopsy method for causes of childhood mortality in Namibia. J Trop Pediatr. 1996:42:365-9.

43. Quigley M, JRM A WS. Algorithms for verbal autopsies: a validation study in Kenyan children. Bull World Health Organ. 1996;74:147-54.

44. Rodriguez L, Reyes H, Tome P, Ridaura C, Flores S, Guiscafre H. Validation of the verbal autopsy method to ascertain acute respiratory infection as cause of death. Indian J Pediatr. 1998;65:579-84.

45. Setel P, Rao C, Hemed Y, Whiting DR, Yang G, Chandramohan D. Core Verbal Autopsy Procedures with Comparative Validation Results from Two Countries. PLoS Med. 2006:3(8):e268.

\section{Submit your next manuscript to BioMed Central and we will help you at every step:}

- We accept pre-submission inquiries

- Our selector tool helps you to find the most relevant journal

- We provide round the clock customer support

- Convenient online submission

- Thorough peer review

- Inclusion in PubMed and all major indexing services

- Maximum visibility for your research

Submit your manuscript at www.biomedcentral.com/submit 